\title{
STUDY OF BACTERIAL INFECTION AND THEIR ANTIBIOTIC SENSITIVITY PATTERN IN BURN WOUNDS
}

Rajpal Kamlesh', Kumar Ajay², Nag Sanjay³, Lal Arjun', Mahto S. P5, Sharma S. N6. Prakash Shankar ${ }^{7}$

${ }^{1}$ Assistant Professor, Department of Microbiology, ANMMCH, Gaya.

${ }^{2}$ Senior Resident, Department of Microbiology, IGIMS, Patna.

${ }^{3}$ Assistant Professor, Department of Microbiology, ANMMCH, Gaya.

${ }^{4}$ Associate Professor, Department of Microbiology, ANMMCH, Gaya.

5 Professor, Department of Microbiology, ANMMCH, Gaya.

${ }^{6}$ Associate Professor, Department of Microbiology, PMCH, Patna.

7 Professor, Department of Microbiology, PMCH, Patna.

ABSTRACT

\section{BACKGROUND}

Infection in the burn patient is a leading cause of morbidity and mortality and remains one of the most challenging concerns for doctors.

Aims and Objectives- Burn wound flora and antibiotic susceptibility pattern change during the course of the patient's hospitalisation. So, the purposes of obtaining routine surveillance culture are: 1 . To provide early identification of organisms colonising the wound, 2. To monitor the effectiveness of current wound treatment, 3. To guide preoperative or empiric antibiotic therapy and 4. To detect any cross colonisation, which occur quickly so that further transmission can be prevented.

\section{MATERIALS AND METHODS}

One hundred and sixteen wound swab samples were collected from acutely burnt patients, being treated in the Rajendra Surgical Ward of the Patna Medical College and Hospital, Patna. This descriptive study was conducted from July 2004 to August 2005.

\section{RESULTS}

The present series of study reveals that out of the total of 116 (i.e. 100\%) samples taken within the first 24 hours, in 26 samples $(22.4 \%)$ the organism isolated was Staphylococcus aureus; in 9 samples (7.75\%) the organism isolated was Staphylococcus epidermidis; in 4 samples (i.e. 3.44\%) the organism isolated was Streptococcus pyogenes; in 4 samples (3.44\%) the organism isolated was Pseudomonas sp. Out of a total of 98 samples (100\%), sample taken at the end of first week in 17 samples i.e. $17.34 \%$ the organism isolated was Staphylococcus aureus and in 2 samples (2.04\%) the organism isolated was Staphylococcus epidermidis; in 3 samples i.e. $3.06 \%$ the organism isolated was Streptococcus pyogenes; in 26 samples i.e. $26.53 \%$ the organism isolated was Pseudomonas aeruginosa; in 9 samples i.e. 9.18\% the organism isolated was Proteus sp.; in 6 samples i.e. 6.12\% the organism isolated was Klebsiella sp.; in 5 samples i.e. $5.10 \%$ the organism isolated was E. coli. Out of a total of 77 samples (100\%) taken at the end of second week, in 10 samples i.e. 13\% the organism isolated was Staphylococcus aureus; in 1 sample i.e. 1.3\% the organism isolated was Staphylococcus epidermidis; in 1 sample i.e. $1.3 \%$ the organism isolated was Streptococcus pyogenes; in 22 samples (28.5\%) the organism isolated was Pseudomonas aeruginosa; in 8 samples (10.4\%) the organism isolated was Proteus sp.; in 4 samples (5.2\%) the organism isolated was Klebsiella sp. and in 4 samples (5.2\%) the organism isolated was E. coli.

\section{CONCLUSION}

In spite of use of effective antimicrobial agents, the problem of control of infection in burn patients still persists. Pseudomonas aeruginosa is still the major pathogen responsible for bacteraemia in burn wound infection. Other important bacteria are Staphylococcus aureus and Proteus sp. Pseudomonas aeruginosa is sensitive to amikacin and ciprofloxacin, Proteus sp. to Ceftriaxone Staphylococcus aureus to cloxacillin, E. coli to ciprofloxacin and Cefotaxime, Klebsiella sp. To ciprofloxacin and gentamycin, Streptococcus pyogenes to cefotaxime and cefoperazone and Staphylococcus epidermidis to cloxacillin and cefazolin of infection by Pseudomonas aeruginosa, Staphylococcus aureus and Proteus sp. are becoming difficult because of the development of resistance to newer antibiotics. So, inadvertent use of antibiotics must be discouraged.

\section{KEYWORDS}

Burn Wound, Antibiotic Sensitivity Pattern.

HOW TO CITE THIS ARTICLE: Kamlesh R, Ajay K, Sanjay N, et al. Study of bacterial infection and their antibiotic sensitivity pattern in burn wounds. J. Evolution Med. Dent. Sci. 2017;6(70):5004-5008, DOI: 10.14260/Jemds/2017/1087

Financial or Other, Competing Interest: None.

Submission 10-05-2017, Peer Review 20-08-2017,

Acceptance 26-08-2017, Published 31-08-2017.

Corresponding Author:

Dr. Kumar Ajay,

Senior Resident,

Department of Microbiology,

Indira Gandhi Institute of Medical Sciences, Patna-14

E-mail:dr.ajay876@gmail.com

DOI: $10.14260 /$ jemds $/ 2017 / 1087$

\section{BACKGROUND}

Infection in the burn patient is a leading cause of morbidity and mortality and remains one of the most challenging concerns for doctors. ${ }^{1}$ The importance of preventing infection has been recognised in organised burn care, since its inception and has followed recurring themes through the years. In spite of use of effective antimicrobial agents, the problem of control of infection in burn cases has not been entirely solved. ${ }^{2}$ The measures taken for infection control in burn patients are strict aseptic technique, use of sterile gloves 
and dressing materials, wearing masks for dressing changes and special separation of patients, either using private rooms or cubicles. There are three conditions which lead to the development of infection in burn patients: Source of organisms, mode of transmission and the susceptibility of the patient. Exogenous organisms from the hospital environment are generally more resistant to antimicrobial agents than endogenous organisms. ${ }^{3}$ All burn wounds become colonised by 72 hrs. after injury with the patient's own flora or with endemic organisms from the treatment facility. Bacteria colonise the surface of the wound and may penetrate the vascular eschar. Even with firm clinical evidence of sepsis, a definitive microbiological diagnosis of infection can sometimes be difficult to obtain. ${ }^{4}$ Blood cultures have a relatively low yield in the burn population and other anatomic sites of potential infection (e.g. wounds, respiratory tract and urine). Organisms may also reach the damaged area from the surrounding skin, clothing and systemic routes. ${ }^{5}$

When the burn wound starts to heal, granulation tissue appears and when the surface is clearing up microclimate changes and gram-positive flora predominantly Staphylococcus comes back. Previously, $\beta$-haemolytic streptococci were identified as the most serious threat and almost all burn patients become infected with this organism at some stage of their stay in hospital, and they often proceeded to a rapidly fatal course. ${ }^{6}$ In recent years, MRSA has become a particularly significant problem in Indian hospitals. The Burn Unit is a particularly fertile environment for MRSA because of open wounds; frequent dressing changes requiring handling by multiple healthcare workers, use of intraluminal devices and the inherent immunocompromised state of burn patients. ${ }^{7}$ Ultimately, the gramnegative organisms emerge as the major cause of death in thermally injured patients. Among these, Pseudomonas aeruginosa was the worst offender. ${ }^{8}$ Majority of the victims of domestic burn are women and children. Patients in the burn ward are prone to cross contamination by airborne spread of the bacteria. Microorganisms carrying burn wound infection must be identified earlier and their sensitivity pattern should be done cautiously by selecting the proper and adequate antibiotics.

\section{MATERIALS AND METHODS}

One hundred and sixteen wound swabs were collected from acutely burnt patients, being treated in the Rajendra Surgical Ward of the Patna Medical College and Hospital, Patna. This descriptive study was conducted from July 2004 to August 2005. The burn patients and their attendants were explained about the nature of the test done and information collected from them in a scheduled proforma as: 1. Serial No., 2. Registration No., 3. Name, 4. Age, 5. Sex, 6. Religion, 7. Occupation, 8. Type of burn, 9. Percent of burn, 10. Interval between burn and admission, and 11. Site from where wound swabs were taken.

Using sterile Dacron swabs, the samples from the burn wounds were taken with all precautions to avoid contamination of specimen with commensal organism from the skin. Samples were taken preferably before an antiseptic dressing was applied. Immediately after taking sample with Dacron swab, inoculation was done in Liver broth and Glucose broth at the bedside of patient. These inoculated media were then labelled and transported to the laboratory. Wound swab from the same wound was taken to the laboratory and smear was prepared on a clean, dry, greasefree slide. By the same time, the wound swab was also inoculated into nutrient agar, blood agar and MacConkey agar media. After heat fixation of smear, it was stained by Gram's method and examined microscopically for the morphological character and staining reaction of the organism first under low power, then under high power objective and finally under oil immersion objective and the results were noted. Intermittent wound swabs were also subjected to culture into same media as mentioned before. The inoculated media were incubated at $37^{\circ} \mathrm{C}$ for $24 \mathrm{hrs}$. and examined for growth of bacteria in different media.

Antibiotic Sensitivity test was performed on MuellerHinton Agar, blood agar and MacConkey Agar plates by KirbyBauer disc diffusion methods.

\section{Statistical Analysis}

The data collected was entered in the Microsoft Excel computer programming and checked for any inconsistency. The results are presented in proportion/percentage.

\section{RESULTS}

One hundred and sixteen wound swab samples were collected from acutely burnt patients, being treated in the Rajendra Surgical Ward of the Patna Medical College and Hospital, Patna. This descriptive study was conducted from July 2004 to August 2005. Cause of burn, age of the patients and positive burn wound swab culture with sex distribution is shown in Tables 1, 2 and 3.

The present series of study reveals that out of the total of 116 (i.e. 100\%) samples taken within the first 24 hours, in 26 samples $(22.4 \%)$ the organism isolated was Staphylococcus aureus; in 9 samples $(7.75 \%)$ the organism isolated was Staphylococcus epidermidis; in 4 samples (i.e. $3.44 \%$ ) the organism isolated was Streptococcus pyogenes; in 4 samples $(3.44 \%)$ the organism isolated was Pseudomonas sp. [Table 4, 5].

Out of a total of 98 samples (100\%) sample taken at the end of first week in 17 samples i.e. $17.34 \%$, the organism isolated was Staphylococcus aureus and in 2 samples $(2.04 \%)$ the organism isolated was Staphylococcus epidermidis; in 3 samples i.e. $3.06 \%$ the organism isolated was Streptococcus pyogenes; in 26 samples i.e. $26.53 \%$ the organism isolated was Pseudomonas aeruginosa; in 9 samples i.e. 9.18\% the organism isolated was Proteus sp.; in 6 samples i.e. 6.12\% the organism isolated was Klebsiella sp.; in 5 samples i.e. $5.10 \%$ the organism isolated was E. coli [Table 4, 5].

Out of a total of 77 samples (100\%) taken at the end of second week, in 10 samples i.e. $13 \%$ the organism isolated was Staphylococcus aureus, in 1 sample i.e. 1.3\% the organism isolated was Staphylococcus epidermidis; in 1 sample i.e. 1.3\% the organism isolated was Streptococcus pyogenes; in 22 samples $28.5 \%$ the organism isolated was Pseudomonas aeruginosa; in 8 samples $10.4 \%$ the organism isolated was Proteus sp.; in 4 samples (5.2\%) the organism isolated was Klebsiella $s p$.; in 4 samples $(5.2 \%)$ the organism isolated was E. coli. [Table 4, 5]. Table 6 shows the number of isolates and their percentage.

Pseudomonas aeruginosa is sensitive to amikacin and ciprofloxacin, Proteus sp. to Ceftriaxone, Staphylococcus aureus to cloxacillin, E. coli to ciprofloxacin and Cefotaxime, Klebsiella sp. to ciprofloxacin and gentamycin, Streptococcus pyogenes to cefotaxime and cefoperazone and Staphylococcus epidermidis to cloxacillin and cefazolin of infection by 
Pseudomonas aeruginosa, Staphylococcus aureus and Proteus sp. are becoming difficult because of the development of resistance to newer antibiotics. So, inadvertent use of antibiotics must be discouraged. Antibiotic sensitivity pattern are given in Table 7 in $100 \%$ sensitive and $100 \%$ resistant form of both gram positive and gram negative organism. We exclude those antibiotics, they are in the form of intermediate.

\begin{tabular}{|c|c|c|}
\hline Cause of Burns & No. of Patients & \% of Patients \\
\hline 1. Thermal burn & 85 & 73.27 \\
\hline 2. Scald burn & 22 & 18.96 \\
\hline 3. Electric burn & 5 & 4.31 \\
\hline 4. Explosive burn & 4 & 3.44 \\
\hline \multicolumn{2}{|c|}{ Table 1. Cause of Burn } \\
\hline
\end{tabular}

\begin{tabular}{|c|c|c|c|c|}
\hline \multirow{2}{*}{ Age in Years } & \multicolumn{2}{|c|}{ No. of Cases and their Percentage } & \multicolumn{2}{|c|}{ No. of Wound Swab Culture Positive and their Percentage } \\
\hline & No & $\%$ & No & $\%$ \\
\hline $0-10$ & 12 & 10.03 & 11 & 9.48 \\
\hline $11-20$ & 32 & 27.5 & 27 & 23.27 \\
\hline $21-30$ & 42 & 36.2 & 31 & 26.72 \\
\hline $31-40$ & 13 & 11.2 & 11 & 9.48 \\
\hline $41-50$ & 10 & 8.62 & 8 & 6.89 \\
\hline$\geq 51$ & 7 & 6.03 & 7 & 6.03 \\
\hline Total & 116 & $100 \%$ & 95 & 81.87 \\
\hline
\end{tabular}

\begin{tabular}{|c|c|c|c|c|}
\hline \multirow{2}{*}{ Sex } & \multicolumn{2}{|c|}{ Total No. of Cases and their Percentage } & \multicolumn{2}{c|}{$\begin{array}{c}\text { No. and Percentage of Positive } \\
\text { Wound Swab Culture (within 24 hrs.) }\end{array}$} \\
\cline { 2 - 5 } & No. & $\%$ & No. & \% \\
\hline Female & 75 & 64.6 & 61 & 29.31 \\
\hline Male & 41 & 35.4 & 34 & \\
\hline Total & 116 & 100 & & \\
\hline \multicolumn{2}{|c|}{ Table 3. Showing Number and Percentage of Positive Burn Wound Swab Culture with Sex Distribution } \\
\hline
\end{tabular}

\begin{tabular}{|c|c|c|c|c|c|}
\hline $\begin{array}{c}\text { No. of Days } \\
\text { of Sample } \\
\text { Taken }\end{array}$ & $\begin{array}{c}\text { Total No. } \\
\text { of Samples } \\
\text { Taken }\end{array}$ & $\begin{array}{c}\text { No. of Samples } \\
\text { showing Positive } \\
\text { Growth }\end{array}$ & $\begin{array}{c}\text { Percentage of Samples } \\
\text { showing Positive Growth }\end{array}$ & $\begin{array}{c}\text { No. of Samples showing } \\
\text { No Growth of } \\
\text { Microorganisms }\end{array}$ & $\begin{array}{c}\text { Percentage of } \\
\text { Samples showing } \\
\text { No Growth of } \\
\text { Microorganisms }\end{array}$ \\
\hline Within first 24 hrs. & 116 & 43 & 37.065 & 73 & 62.93 \\
\hline $\begin{array}{c}\text { At the end of first } \\
\text { week }\end{array}$ & 98 & 68 & 69.38 & 30 & 30.61 \\
\hline $\begin{array}{c}\text { At the end of } \\
\text { second week }\end{array}$ & 77 & 50 & 65 & 27 & 35 \\
\hline
\end{tabular}

Table 4. Showing the Total Number and Percentage of Positive and Negative Cases of Wound Swab Culture of Samples taken, within 24 hours of Admission, at the end of First Week and at the End of Second Week

\begin{tabular}{|c|c|c|c|c|c|c|}
\hline \multirow[t]{2}{*}{$\begin{array}{c}\text { Organism } \\
\text { Isolated }\end{array}$} & \multicolumn{2}{|c|}{$\begin{array}{c}\text { No. and \% of Positive } \\
\text { Wound Swab Cultures of } \\
\text { Samples taken within } 24 \\
\text { hrs. of Admission }(n=116)\end{array}$} & \multicolumn{2}{|c|}{$\begin{array}{c}\text { No. and \% of Positive } \\
\text { Wound Swab Cultures } \\
\text { of Samples taken at the } \\
\text { End of First Week }(n=98)\end{array}$} & \multicolumn{2}{|c|}{$\begin{array}{c}\text { No. and \% of Positive } \\
\text { Wound Swab Cultures } \\
\text { of Samples taken at the } \\
\text { End of Second Week }(n=77)\end{array}$} \\
\hline & No. & $\%$ & No. & $\%$ & No. & $\%$ \\
\hline Staphylococcus aureus & 26 & $22.4 \%$ & 17 & $17.34 \%$ & 10 & 13 \\
\hline Staphylococcus epidermidis & 9 & $7.75 \%$ & 2 & 2.04 & 1 & 1.3 \\
\hline Pseudomonas aeruginosa & 4 & $3.44 \%$ & 26 & 26.53 & 22 & 28.5 \\
\hline Proteus sp. & & & 9 & 9.18 & 8 & 10.4 \\
\hline E. coli & & & 5 & 5.10 & 4 & 5.2 \\
\hline Klebsiella sp. & & & 6 & 6.12 & 4 & 5.2 \\
\hline Streptococcus pyogenes & 4 & $3.44 \%$ & 3 & 3.06 & 1 & 1.3 \\
\hline
\end{tabular}

\begin{tabular}{|c|c|c|}
\hline Organism Isolated & Number & Percentage \\
\hline Pseudomonas aeruginosa & 52 & 47.86 \\
\hline Staphylococcus epidermidis & 12 & 5.84 \\
\hline Proteus sp. & 17 & 18.21 \\
\hline Staphylococcus aureus & 53 & 3.09 \\
\hline E. coli & 9 & 3.43 \\
\hline Klebsiella sp. & 10 & 2.74 \\
\hline Streptococcus pyogenes & 8 & $\mathbf{5 5 . 2 9}$ \\
\hline Total & $\mathbf{1 6 1}$ \\
\hline
\end{tabular}




\begin{tabular}{|c|c|c|}
\hline $\begin{array}{l}\text { Organism } \\
\text { Isolated }\end{array}$ & $\begin{array}{c}\text { Sensitive to } \\
(100 \%)\end{array}$ & (100\%) \\
\hline $\begin{array}{r}\text { Pseudom } \\
\text { aerugin }\end{array}$ & $\begin{array}{r}\text { Am } \\
\text { Cipro }\end{array}$ & $\begin{array}{l}\text { Cloxacillin, lon } \\
\text { Cotrimoxazole }\end{array}$ \\
\hline Pro & Ceftr & $\begin{array}{r}\text { Ceftriaxor } \\
\text { Ampicillin, }\end{array}$ \\
\hline aut & Cloxa & $\begin{array}{c}\begin{array}{c}\text { Gentamycin, Cotrimoxazole, } \\
\text { Lomefloxacin }\end{array} \\
\end{array}$ \\
\hline E. coli & in, & $\begin{array}{r}\text { Amikacir } \\
\text { Lomefloxaci }\end{array}$ \\
\hline Klebsiella sp. & genta & $\begin{array}{r}\text { Ampicillin } \\
\text { Lome }\end{array}$ \\
\hline Strep & Cefotax & $\begin{array}{r}\text { Cotrimoxazo } \\
\text { Amikacin }\end{array}$ \\
\hline $\begin{array}{l}\text { Staph. } \\
\text { epidermidis }\end{array}$ & $\begin{array}{r}\text { Clox } \\
\text { Cef }\end{array}$ & $\begin{array}{c}\text { Ceftriaxone, Cotrimoxazole, } \\
\text { Ampicillin, Amikacin, } \\
\text { Gentamycin }\end{array}$ \\
\hline \multicolumn{3}{|c|}{$\begin{array}{l}\text { Table 7. Showing Antibiotic Sensitivity Pattern of Isolates } \\
\text { of Wound Swab Culture }\end{array}$} \\
\hline
\end{tabular}

\section{DISCUSSION}

In the present series, it is seen that out of a total of 116 samples of wound swab taken within $24 \mathrm{hrs}$. of admission, 43 samples showed positive growth of microorganisms with a percentage of $37.06 \%$. Again, samples of wound swab taken at the end of first week shows that the percentage of infection has increased up to $69.38 \%$. This increase in the infection rate is because of hospital acquired infections. All burn wounds become colonised by 72 hrs. after injury with the patient's own flora or with endemic organisms from the treatment facility. ${ }^{9}$

The bacteria which grow in samples was taken within 24 hrs. of admission are mostly of autogenous source and they are virgin strains sensitive to most of antibiotics.

The bacteria which grow in samples taken at the end of first week and at the end of second week are mostly from nosocomial infection, and they were resistant to most of the antibiotics the first hour only resident bacteria of the skin which are mostly Gram positive predominate in burn wounds. Thus, Staphylococcus epidermidis is replaced by Staphylococcus aureus within few hours of burn injury. This is known as Gram positive period.

Then comes the period of Gram negative and Grampositive bacteria. As the time passes, Gram positive bacteria slowly begins to disappear and Gram-negative bacteria appear and their number slowly begins to rise. ${ }^{10}$

Then comes the Gram-negative period, when the eschar begins to slough. When the wound starts to heal, again Grampositive flora predominates and ultimately upon healing resident flora of skin reoccupy the skin.

Martin E. Plant, 1976 has also observed the similar findings stating that sepsis of burns is mostly due to hospital infection and Staphylococcus aureus isolated in hospital show resistance to most of the antibiotics.

Around one week after burn injury, the organism started entering the blood from the surfaces causing bacteraemia and septicaemia.

In the present series, it has been observed that Pseudomonas aeruginosa is mostly sensitive to Amikacin and Ciprofloxacin; $38.46 \%$ isolates are sensitive to Amikacin and $42.3 \%$ isolates are sensitive to Ciprofloxacin; $75.5 \%$ isolates of Staphylococcus aureus are sensitive to Cloxacillin; 98\% isolates of Proteus sp. are sensitive to Ceftriaxone; 44.4\% isolates of E. coli are sensitive to Ciprofloxacin and 55.5\% isolates are sensitive to Cefotaxime.

$50 \%$ isolates of Klebsiella sp. are sensitive to Ciprofloxacin and $50 \%$ isolates to Gentamycin; $75 \%$ isolates of Streptococcus pyogenes are sensitive to Cefotaxime and $12.5 \%$ are sensitive to Cefoperazone; $83.3 \%$ isolates are sensitive to Cloxacillin and $8.3 \%$ isolates are sensitive to Cefazolin.

It has also been observed that most of the isolates show resistance to some antibiotics. In this study, it has been seen that Pseudomonas aeruginosa is resistant to cloxacillin, lomefloxacin, cotrimoxazole and ampicillin. Staphylococcus aureus is resistant to gentamycin, cotrimoxazole and lomefloxacin. E. coli is resistant to amikacin, cloxacillin, lomefloxacin, cefotaxime and cotrimoxazole.

Klebsiella $s p$. is resistant to ampicillin, cloxacillin and lomefloxacin. Streptococcus pyogenes is resistant to cotrimoxazole, ciprofloxacin, amikacin and gentamycin. Staphylococcus epidermidis is resistant to ceftriaxone, cotrimoxazole, ampicillin, amikacin and gentamycin.

This increasing tendency to bacterial resistance is because of inadvertent use of antibiotics in burn cases. Here, lies the importance of bacteriological isolation and its proper antibiotic selection to avoid use of unnecessary antibiotic administration to the patient.

Above facts are also accepted by Joan Weber, RN Albert McManus 1990. They stated that systemic antimicrobial treatment must be thoughtfully considered in the care of burn patients to prevent the emergence of resistant organisms.

Organism isolated in blood culture also shows the same sensitivity pattern as that of isolates of wound swab culture.

The above findings are also shown by Jackson, Lowbury and Topley 1951, who stated that incidence of Pseudomonas infection in burns is rising and is likely to cause fatal septicaemia.

Blach 1965, stated that septicaemia is more common in severely burned patients and microorganisms isolated from the blood stream are usually found in the burn wound.

\section{CONCLUSION}

In spite of use of effective antimicrobial agents, the problem of control of infection in burn patients still persists. Most of the burn wounds become colonised by 72 hrs. of injury with the patient's own flora or with endemic organisms from the treatment facility. In cases of burn wounds, it is important to do an immediate infection workup and administer the appropriate antibiotics. Patients in the burn ward are more prone to cross contamination by air borne spread of the bacteria. Beddings, pillows, blankets and mattresses are proved to be the reservoir of microorganisms. Thermal burn is the most common type of burn. Next is the scald burn, which is more common among children. Young females, mostly those involved in domestic works are the major victims of burn injury. Most common isolates from upper extremity are gram positive cocci, whereas most common isolates from lower extremity, back, perineum, buttocks and thigh are gram negative bacilli. Pseudomonas aeruginosa is still the major pathogen responsible for bacteraemia in burn wound infection. Other important bacteria are Staphylococcus aureus and Proteus sp. Pseudomonas aeruginosa is sensitive 
to amikacin and ciprofloxacin, Proteus sp. to gatifloxacin, Staphylococcus aureus to cloxacillin, E. coli to ciprofloxacin and gatifloxacin, Klebsiella sp. to gatifloxacin and gentamycin, Streptococcus pyogenes to cefotaxime and cefoperazone and Staphylococcus epidermidis to cloxacillin and cefazolin. Control of infection by Pseudomonas aeruginosa, Staphylococcus aureus and Proteus sp. is becoming difficult because of the development of resistance to newer antibiotics. So, inadvertent use of antibiotics must be discouraged. If antimicrobial therapy is indicated to treat specific infection, it should be tailored to the specific susceptibility pattern of the organisms as soon as this information is available. Most of the cases of late arrival in hospital show growth of microorganisms in wound swab culture.

\section{REFERENCES}

[1] Alborzi A, Pourabbas BA, Salehi H, et al. Prevalence and pattern of antibiotic sensitivity of methicillin sensitive and resistant staphylococcus aureus in Shiraz-Iran. Ind J Med Science 2000;25:1-8.

[2] Barillo DJ, Brigham PA, Kayden DA, et al. Burn wound infection: the fire safe. A burn Prevention toolrette 1998;22:134-45.
[3] David N, Herndon A. Research program report in Shriners burn hospital Galveston, Texas 2004.

[4] Herndon DN, Spies M. Modern burn care. Semin Pediatr Surg 2001;10(1):28-31.

[5] Alekseev AA, Iakovlev VP, Fedorov VD. Infection in burn patients: the problems of pathogenesis, prevention and treatment. Khirurgiia (Mosk) 1999;6:4-9.

[6] Kauvar DS, Acheson E, Reeder J, et al. Comparison of battlefield-expedient topical antimicrobial agents for the prevention of burn wound sepsis in a rat model. Journal of Burn care and Rehabilitation 2005;26(4):357-61.

[7] Keen A, Knoblock L, Edelman L, et al. Effective limitation of blood culture use in the burn unit. J Burn Care Rehabil 2002;23(3):183-9.

[8] Mayhall CG. The epidemiology of burn wound infections: then and now. Clin infect Dis 2003;37(4):543-50.

[9] Santucci SG, Gobara S, Santos CR, et al. Infections in a burn intensive care unit: experience of seven years. J Hosp infect 2003;53(1):6-13.

[10] Weber JM, Sheridan RL, Peterson HF, et al. Central venous catheter sepsis with weekly catheter changes in paediatric burn patients: an analysis of 221 catheters. Burns 1995;21(2):127-9. 